\title{
Identifying Reaction Species by Evolutionary Fitting and Kinetic Analysis: An Example of $\mathrm{CO}_{2}$ Hydrogenation in DRIFTS
}

\author{
Kun Zhao, ${ }^{*},, \|, \perp \odot$ Ligang Wang, ${ }^{\dagger, \S, \perp}$ Emanuele Moioli, ${ }^{\dagger, \|}$ Marco Calizzi, ${ }^{*},, \|_{\odot}$ and Andreas Züttel ${ }^{\dagger, \|}$ \\ ${ }^{\dagger}$ Laboratory of Materials for Renewable Energy, Institute of Chemical Sciences and Engineering, ${ }^{\ddagger}$ Group of Energy Materials, \\ Institute of Mechanical Engineering, and ${ }^{\S}$ Industrial Process and Energy Systems Engineering, Institute of Mechanical Engineering, \\ École Polytechnique Fédérale de Lausanne (EPFL), 1951 Sion, Switzerland \\ "Swiss Federal Laboratories for Materials Science and Technology (EMPA), 8600 Dübendorf, Switzerland
}

\section{Supporting Information}

ABSTRACT: Diffuse reflectance infrared Fourier transform spectroscopy (DRIFTS) investigations of molecules at the surface of catalysts exhibit a strong overlap of the adsorption peaks. Therefore, the investigation of the $\mathrm{CO}_{2}$ hydrogenation on a highly active catalyst surface requires a deconvolution of the adsorption spectra to clearly assign the signal to the chemical species. We developed an autonomous and efficient bi-level evolutionary Gaussian fitting (BEGF) procedure with a genetic algorithm at the upper level and a multipeak Gaussian fitting algorithm at the lower level to analyze self-consistently the set of spectra of an entire experiment. We show two examples of the application of BEGF procedure by analyzing the DRIFTS spectral sets of ex situ $\mathrm{HCOO}^{-*}$ and $\mathrm{CO}_{2}$ hydrogenation on $\mathrm{Ru} / \mathrm{Al}_{2} \mathrm{O}_{3}$. The fitting procedure deconvoluted the overlapped peaks and identified the bond vibrations of carbon monoxide, formate, bicarbonate, and carbonate through the developing trends of the peak intensities along the reaction. These revealed the progression of those species over the reaction timeline.

\section{INTRODUCTION}

Heterogeneous catalysis on surfaces, such as $\mathrm{CO}_{2}$ hydrogenation catalysis, has been widely studied by diffuse reflectance infrared Fourier transform spectroscopy (DRIFTS), as both the gas-phase components and the surface adsorption species can be detected in situ and in operando. ${ }^{1-7}$ The correct assignment of the infrared (IR) peaks is not easy because they are strongly overlapped. Especially, the $\mathrm{O}-\mathrm{C}-\mathrm{O}$ asymmetric stretching modes of $\mathrm{HCO}_{3}^{-}, \mathrm{HCOO}^{-}, \mathrm{COOH}^{-}$, and bent $\mathrm{CO}_{2}{ }^{\delta-}$ share very close positions in the range of $1800-1300$ $\mathrm{cm}^{-1}$. This has led to discrepant explanations of the production of the adsorption species, thence diverse reaction pathways about either bicarbonate, formate, or carbon monoxide is the key intermediate. ${ }^{7,9-11}$ Many issues affect the analysis of $\mathrm{CO}_{2}$ hydrogenation using IR spectroscopy. First, the determination of the IR peak positions of the species present on reactive surfaces such as $\mathrm{Ru}, \mathrm{Rh}, \mathrm{Pd}$, etc. is not simple due to the strong overlap of the peaks. As a result, the manual assignment of the peak positions among the multipeaks and shoulders does not have an obvious unique solution. Second, some subpeaks in the overlapped region vanish or appear during the reaction, which is easily neglected in the analysis. Thus, assigning the peaks using data only at one or a few stages in the reaction can lose information. A global analysis of the spectra done over the entire course of the reaction is necessary. This brings us to the third issue: there is no efficient procedure to fit self-consistently the peaks of all of the spectra recorded during the reaction. Fitting spectra non- self-consistently, or using inconsistent parameters, can give an incorrect description of the development of the peaks along the reaction coordinate. A multipeak Gaussian curve fitting can be performed with nonlinear gradient-based solvers, ${ }^{12}$ but the results depend strongly on the guesses of initial values and bounds of the parameters related to each peak. Bad guesses lead the solvers to be trapped at local optima, resulting in unsatisfactory or even wrong results.

Here, we tackle the three issues just raised by developing a novel bi-level evolutionary Gaussian fitting (BEGF) procedure to fit the peaks from a set of spectra and select the reasonably deconvoluted peaks automatically. This BEGF procedure combines gradient-free evolutionary algorithms at the upper level and nonlinear multipeak Gaussian fittings at the lower level to optimize the peaks. An evolutionary algorithm is an optimization algorithm that ranks the candidate solutions, recombines the parameters of the best ones to create a new generation of candidate solutions, and iterates till convergence is reached. ${ }^{13}$ The evolutionary algorithm overcomes the problem of Gaussian fitting being trapped at local optima. The fitting results elucidate the developing trends of the resolved peaks along the reaction. According to the similarities of the peak developments in the reaction, and combined with the peak positions from the standard samples such as formic

Received: November 15, 2018

Revised: February 27, 2019

Published: March 11, 2019 
acid $(\mathrm{HCOOH})$, sodium carbonate $\left(\mathrm{Na}_{2} \mathrm{CO}_{3}\right)$, calcium carbonate $\left(\mathrm{CaCO}_{3}\right)$, sodium bicarbonate $\left(\mathrm{NaHCO}_{3}\right)$, and potassium bicarbonate $\left(\mathrm{KHCO}_{3}\right)$, the peaks were clearly assigned to the bond vibrations of the specific species.

In the next section, we provide a description of the BEGF algorithm. More detailed information and the MATLAB code used for the work reported here are given in the Supporting Information (SI). Later on, we describe the procedure with two examples: (1) formate hydrogenation where formate was from an $\mathrm{HCOOH}$ droplet and therefore named as ex situ $\mathrm{HCOO}^{-*}$ to distinguish the formate formed from the $\mathrm{CO}_{2}$ hydrogenation process; (2) $\mathrm{CO}_{2}$ hydrogenation. These two examples show how the procedure helps the assignment of the peaks and analyze the reactive progression of the reaction species.

\section{FITTING AND EXPERIMENTAL METHODS}

2.1. Bi-Level Evolutionary Gaussian Fitting (BEGF)

Procedure. The multipeak Gaussian fitting is a least-square problem (eq 1a), which minimizes the sum of squared errors between the fitted value and the experimental data of the spectrum to find the best fit

$$
\begin{aligned}
\min _{\mathbf{a}, \mathbf{b}, \mathbf{c}} f & =\sum_{i=1}^{N_{\mathrm{s}}}\left(\sum_{j=W_{\mathrm{s}}}^{W_{\mathrm{e}}}\left(Y_{i, j}\left(\mathbf{a}_{i}, \mathbf{b}, \mathbf{c}_{i}\right)-Y_{i, j}^{*}\right)^{2}\right), \\
\mathbf{a}_{i} & =\left\{\ldots a_{i, k} \ldots\right\}, \mathbf{b}=\left\{\ldots b_{k} \ldots\right\}, \mathbf{c}_{i}=\left\{\ldots c_{i, k} \ldots\right\}
\end{aligned}
$$

with

$$
Y_{i, j}=\sum_{k=1}^{N_{\text {peak }}} a_{i, k} \mathrm{e}^{-\left(x-b_{k} / c_{i, k}\right)^{2}}
$$

where $i$ stands for the ith spectrum in the total $N_{\mathrm{s}}$ spectra and $j$ is the wavenumber within the defined range $\left[W_{s}, W_{\mathrm{e}}\right]$, where $W_{\mathrm{s}}$ and $W_{\mathrm{e}}$ are the starting and ending wavenumbers, respectively. $Y_{i, j}$ and $Y_{i, j}^{*}$ are the fitted and measured values, respectively. The variables $a_{i, k}, b_{k}$, and $c_{i, k}$ are the height, position, and width, respectively, of each Gaussian peak $k(1 \leq$ $\left.k \leq N_{\text {peak }}\right) . a_{i}$ and $c_{i}$ vary along the reaction, whereas $b$ is generally assumed not to change as the reaction proceeds.

The optimization problem is highly nonlinear due to the Gaussian function used in the definition of $Y_{i, j}$ (eq $1 b$ ). The whole problem can be solved by gradient-based solvers. However, in our experience with fitting DRIFTS spectra, gradient-based solvers get trapped at local minima depending on the guesses of the initial values of Gaussian parameters, and these guesses are usually obtained manually by timeconsuming trial-and-error.

To overcome this difficulty, we decomposed the mathematical optimization problem into two levels: for the upper level, we used a genetic algorithm to provide initial values for a multipeak Gaussian fitting algorithm used on the lower level.

The scheme of the BEGF process is shown in Figure 1, with the problem decomposition described as follows:

Upper level

$$
\begin{aligned}
\min _{\mathbf{I}, \mathbf{L}, \mathbf{U}} & \sum_{i=1}^{N_{\mathrm{S}}} \delta_{i}(\mathbf{I}, \mathbf{L}, \mathbf{U}), \mathbf{I}=\left\{\ldots\left\{I_{a_{k}}, I_{b_{k}}, I_{c_{k}}\right\} \ldots\right\} \\
\mathbf{L} & =\left\{\ldots\left\{L_{a_{k}}, L_{b_{k}}, L_{c_{k}}\right\} \ldots\right\}, \mathbf{U}=\left\{\ldots\left\{U_{a_{k}}, U_{b_{k}}, U_{c_{k}}\right\} \ldots\right\}
\end{aligned}
$$

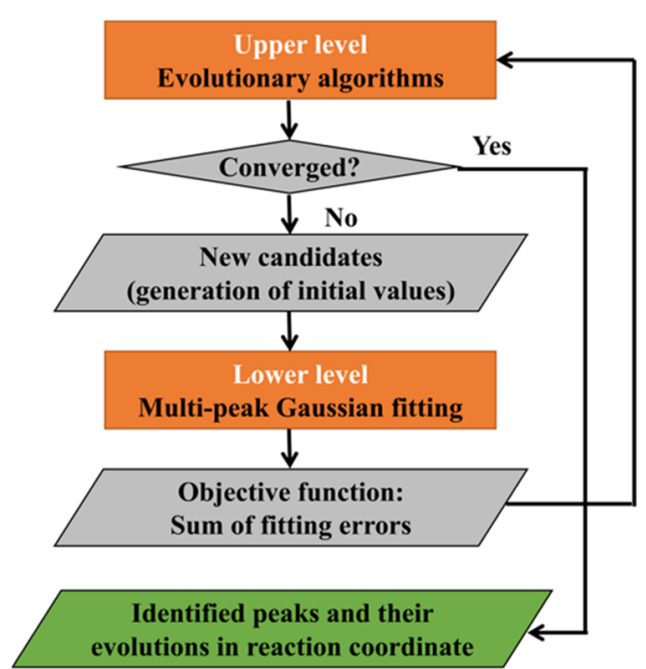

Figure 1. Developed bi-level evolutionary Gaussian fitting algorithm.

Lower level

$$
\begin{aligned}
& \min _{\mathbf{a}, \mathbf{b}, \mathbf{c}} \delta_{i}\left(\mathbf{a}_{i}, \mathbf{b}, \mathbf{c}_{i}\right)=\min _{\mathbf{a}, \mathbf{b}, \mathbf{c}} \sum_{j=W_{\mathrm{s}}}^{W_{\mathrm{e}}}\left(Y_{i, j}-Y_{i, j}^{*}\right)^{2} \\
& =\min _{\mathbf{a}, \mathbf{b}, \mathbf{c}} \sum_{j=W_{\mathrm{s}}}^{W_{\mathrm{e}}}\left(\sum_{k=1}^{N_{\text {peak }}}\left(a_{i, k} \mathrm{e}^{-\left(x-b_{k} / c_{i, k}\right)^{2}}\right)-Y_{i, j}^{*}\right)^{2} \\
& \mathbf{a}_{i}=\left\{\ldots a_{i, k} \ldots\right\}, \mathbf{b}=\left\{\ldots b_{k} \ldots\right\}, \mathbf{c}_{i}=\left\{\ldots c_{i, k} \ldots\right\} \text { subject to } \\
& L_{a_{k}} \leq a_{i, k} \leq U_{a_{k}}, L_{b_{k}} \leq b_{k} \leq U_{b_{k}}, L_{c_{k}} \leq c_{i, k} \leq U_{c_{k}}
\end{aligned}
$$

where $I$ shows the initial values of the parameters ( $a$ height, $b$ position, and $c$ width) of the Gaussian peaks. $L$ and $U$ are the lower and upper bounds of the parameters of the Gaussian peaks, respectively, which are used to constrain the multipeak Gaussian fitting.

The BEGF algorithm works as follows and is sketched in Figure 1. The original spectra are first corrected by subtracting a baseline, which was taken as a straight line between the end points of the defined wavenumber range. The baselinecorrected spectra are used in each run of the low-level algorithm. The solving procedure starts from the upper-level algorithm by generating a number of global candidate solutions [individuals, represented by a set of values of $I, L$, and $U$ (eq 2), which are randomly generated within the user-specified bounds] to form an initial population. Each individual of the population is passed to the lower-level algorithm to obtain the best fit values for the parameters $\boldsymbol{a}_{i}, \boldsymbol{b}$, and $\boldsymbol{c}_{i}$ and to assign the sum of the fitting errors as the value of the objective function (eq 3). The evaluated individual is then passed back to the upper-level algorithm. After evaluating all individuals in the initial population, the upper-level algorithm compares the individuals and discards those with large errors. Afterward, the population starts to evolve iteratively by selecting some existing individuals as parents and generating a new individual as a child with certain crossover and mutation mechanisms. The newly generated child individual is further evaluated in the lower level, returned to the upper level with the objective value, and compared with the parent individuals. The child individual will be preserved if better than the parents, otherwise discarded. In such a way, the whole population is updated by always keeping the better individuals until convergence is reached: no better individual is found after a 
number of latest individual evaluations. The rate of convergence depends on the complexity of the spectra.

The BEGF algorithm starts with a user-specified number of Gaussian peaks. The redundant Gaussian peaks are removed when the $L_{a_{k}}$ and $U_{a_{k}}$ for peak $k$ optimized at the upper level reach zero simultaneously.

Although good initial guesses are not needed for the genetic algorithm, using apparent information of the peaks in the spectra as initial values reduces the search time. Further details of the algorithm, including a MATLAB code implementation, are given in the SI.

Our bi-level algorithm is distinguished from available fitting codes by the following features: (1) It consistently fits the peaks in a given range of wavelengths across the entire set of spectra measured during a reaction; (2) the number of Gaussian peaks used for fitting is determined automatically; (3) the centroid of a given peak is identical for all spectra; (4) peak evolution directly gives the kinetics of the species; (5) manual intervention is not needed; and (6) good initial guesses are not necessary.

2.2. Experimental Methods. Ex situ $\mathrm{HCOO}^{-*}$ and $\mathrm{CO}_{2}$ hydrogenation on $\mathrm{Ru} / \mathrm{Al}_{2} \mathrm{O}_{3}$ (Sigma-Aldrich, 0.5 wt \% loading on $3.2 \mathrm{~mm}$ pellets of $\mathrm{Al}_{2} \mathrm{O}_{3}$ ) pellets and $\mathrm{Al}_{2} \mathrm{O}_{3}$ (Sigma-Aldrich) pellets were carried out in the reaction chamber (HVC, Harrick Scientific) of DRIFTS (Bruker Tensor 27).

Ex situ $\mathrm{HCOO}^{-*}$ was obtained by adding one drop of formic acid onto the surface of $\mathrm{Ru} / \mathrm{Al}_{2} \mathrm{O}_{3}$ or $\mathrm{Al}_{2} \mathrm{O}_{3}$ exposed to air, followed by pumping for $24 \mathrm{~h}$ to reach a vacuum of $5 \times$ $10^{-3}$ mbar at room temperature (RT) in DRIFTS. The hydrogenation of $\mathrm{HCOOH}$ on $\mathrm{Ru} / \mathrm{Al}_{2} \mathrm{O}_{3}$ and $\mathrm{Al}_{2} \mathrm{O}_{3}$ was performed by heating in 1 bar $\mathrm{H}_{2}$ from $\mathrm{RT}$ to $350{ }^{\circ} \mathrm{C}$ at a rate of $1{ }^{\circ} \mathrm{C} / \mathrm{min}$ in DRIFTS.

$\mathrm{CO}_{2}$ hydrogenation was performed by mixing $200 \mathrm{mbar}$ of $\mathrm{CO}_{2}$ and $800 \mathrm{mbar}$ of $\mathrm{H}_{2}$ at $\mathrm{RT}$ and heating to $300{ }^{\circ} \mathrm{C}$ at a rate of $1{ }^{\circ} \mathrm{C} / \mathrm{min}$ on $\mathrm{H}_{2}$-pretreated $\mathrm{Ru} / \mathrm{Al}_{2} \mathrm{O}_{3}$ and $\mathrm{Al}_{2} \mathrm{O}_{3}$ in DRIFTS, as in our previous work. ${ }^{14}$

\section{RESULTS AND DISCUSSION}

Ex situ $\mathrm{HCOO}^{-*}$ and $\mathrm{CO}_{2}$ hydrogenations were used as reaction models for showing the complex spectra and how the BEGF program resolves the peak positions and variations. Formate is one of the intermediates of $\mathrm{CO}_{2}$ hydrogenation. For this reason, we first analyzed the spectra of $\mathrm{HCOOH}$ hydrogenation to understand the reactivities of ex situ formate (ex situ $\mathrm{HCOO}^{-*}$ ) in $\mathrm{H}_{2}$ thermal reduction and then turned to the analysis of $\mathrm{CO}_{2}$ hydrogenation.

3.1. BEGF Analysis of the Spectra of Ex Situ $\mathrm{HCOO}^{-*}$ Hydrogenation. 3.1.1. Convergence of Fitting. The error evolution approaching convergence as a function of time and iteration numbers is illustrated in Figure 2a for the fitting in the range of $1800-1500 \mathrm{~cm}^{-1}$ from 20 to $220{ }^{\circ} \mathrm{C}$, noting that above $220^{\circ} \mathrm{C}$ the peaks and the baseline in this range changed significantly. Re-confining the range of the spectra above 220 ${ }^{\circ} \mathrm{C}$ for the new baseline correction is not necessary but is helpful in shortening the entire fitting time. We compared the fitting with coarse initial values from wide bounds and with fine initial values from readings of the spectra. Around $4 \mathrm{~h}$ were taken for the coarse initial values to reach convergence, with around 4000 iterations, and around $1 \mathrm{~h}$ for the convergence of fine initial values, with around 3000 iterations. The average time of iteration in Figure $2 b$ decreased during evolution because the improved guesses (i.e., $I, L$, and $U$ ) in the iteration
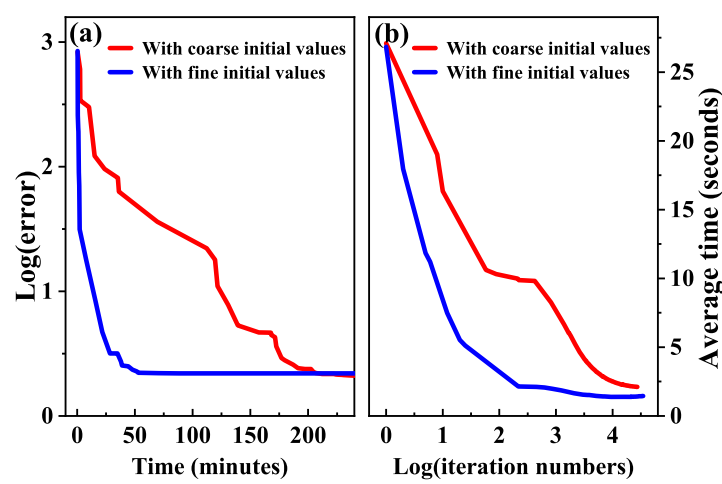

Figure 2. (a) Error evolution approaching convergence as a function of time and (b) average time of iteration for the fitting in the range of $1800-1500 \mathrm{~cm}^{-1}$ from 20 to $220{ }^{\circ} \mathrm{C}$ by BEGF.

reduced the time for each run of lower-level Gaussian fitting. Especially, with fine bounds of $I, L$, and $U$ (blue line), the average time of iteration was shorter in the beginning due to the better solutions from the good bounds, which was beneficial in generating even better initial values for the next iteration. After enough iterations, the competitiveness of the preserved solutions for both blue and red lines became similar, as shown by the similarly converging average time after around 4000 iterations in Figure $2 \mathrm{~b}$.

3.1.2. Assignment of Adsorption Species Based on the Kinetic Results. The fitted spectra at $100,150,200$, and $250^{\circ} \mathrm{C}$ are shown in Figure 3a. Although the peaks are discernible, the evolution of the peak intensities along the reaction is not easily understandable by first sight of the spectra. We then used the BEGF program to produce the integrated intensities of each peak throughout the spectral set so that we obtained the evolution profile of each peak as a function of temperature. The intensity progression both facilitated the assignments of the peaks to specific species and revealed the reactivity of each species during the catalytic reaction.

As shown in Figure $3 \mathrm{~b}, \mathrm{c}, \mathrm{O}-\mathrm{C}-\mathrm{O}$ asymmetric stretching (1560 and $1618 \mathrm{~cm}^{-1}$; the assignments refer to Section S1.1 in SI) decreased from $200{ }^{\circ} \mathrm{C}$ until full reduction at $250{ }^{\circ} \mathrm{C}$. The unassigned peaks at 1415 and $1405 \mathrm{~cm}^{-1}$ showed the same trend as $\mathrm{O}-\mathrm{C}-\mathrm{O}$ asymmetric stretching. By comparing that the relative intensity of the peak $1415 \mathrm{~cm}^{-1}$ to the peak 1405 $\mathrm{cm}^{-1}$ had a much stronger intensity on $\mathrm{Al}_{2} \mathrm{O}_{3}$ than on $\mathrm{Ru} /$ $\mathrm{Al}_{2} \mathrm{O}_{3}$ (Figure $3 \mathrm{~b}, \mathrm{c}$ and Figure $\mathrm{S} 2 \mathrm{a}-\mathrm{c}$ ), the peak $1415 \mathrm{~cm}^{-1}$ was associated with the peak 1560 and $1405 \mathrm{~cm}^{-1}$ was associated with $1618 \mathrm{~cm}^{-1}$. Since $1560 \mathrm{~cm}^{-1}$ had been paired with $1360 \mathrm{~cm}^{-1}$ as $\mathrm{O}-\mathrm{C}-\mathrm{O}$ asymmetric and symmetric stretchings on $\mathrm{Al}_{2} \mathrm{O}_{3}$ (Section $\mathrm{S} 1.2$ in $\mathrm{SI}$ ), $1415 \mathrm{~cm}^{-1}$ could be assigned to $\mathrm{C}-\mathrm{H}$ bending to complete the vibration modes of this species. Thence, the peak at $1405 \mathrm{~cm}^{-1}$ could be either $\mathrm{C}-$ $\mathrm{H}$ bending or $\mathrm{O}-\mathrm{C}-\mathrm{O}$ symmetric stretching, associated with the peak at $1618 \mathrm{~cm}^{-1}$. The remaining three peaks at 1592 , 1390 , and $1375 \mathrm{~cm}^{-1}$ varied in the same trend (Figure 3d). In view that $1592 \mathrm{~cm}^{-1}$ was in the region of $\mathrm{O}-\mathrm{C}-\mathrm{O}$ asymmetric stretching, and was absent on $\mathrm{Al}_{2} \mathrm{O}_{3}$ under all experimental conditions (Figures S1 and S2), we assigned this peak to the $\mathrm{O}-\mathrm{C}-\mathrm{O}$ asymmetric stretching of formate on $\mathrm{Ru}$ sites. The other two peaks at 1390 and $1375 \mathrm{~cm}^{-1}$ were assigned to the $\mathrm{C}-\mathrm{H}$ bending and $\mathrm{O}-\mathrm{C}-\mathrm{O}$ symmetric stretching, respectively, of this structure of formate. These assignments are consistent with the reported values. ${ }^{1,7}$ The combinational vibration of $\mathrm{C}-\mathrm{H}$ bending and $\mathrm{O}-\mathrm{C}-\mathrm{O}$ asymmetric 

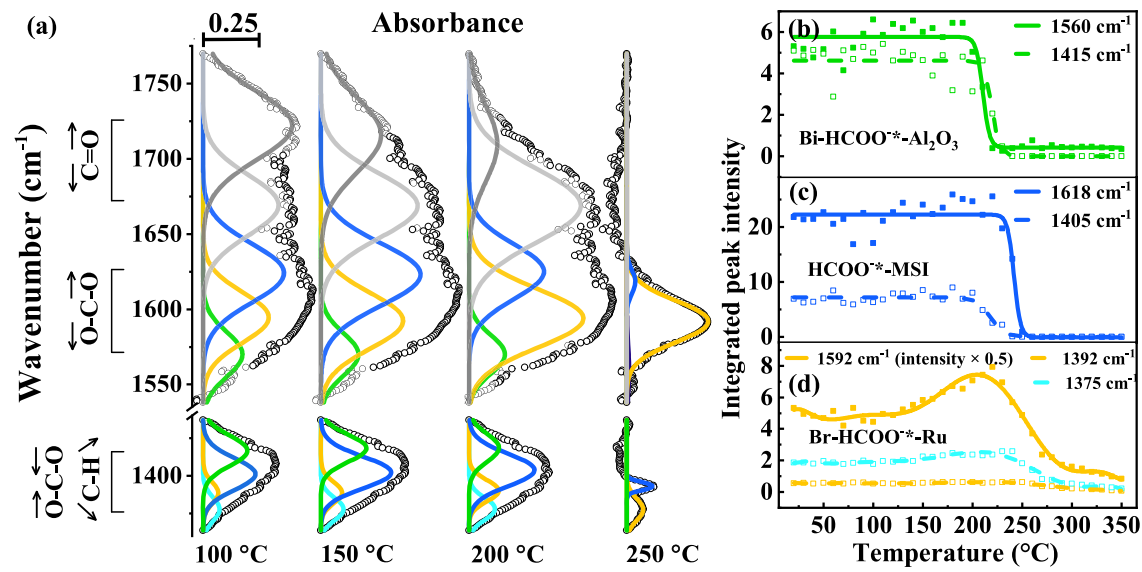

Figure 3. (a) Experimental spectra of ex situ $\mathrm{HCOO}^{-*}$ hydrogenation on $\mathrm{Ru} / \mathrm{Al}_{2} \mathrm{O}_{3}$ (black circles) with fitted peaks (colored lines) in the ranges of $1770-1538$ and $1440-1360 \mathrm{~cm}^{-1}$. The fitting result of the evolution of (b) Bi- $\mathrm{HCOO}^{-*}-\mathrm{Al}_{2} \mathrm{O}_{3},(\mathrm{c}) \mathrm{HCOO}^{-*}-\mathrm{MSI}$, and (d) Br-HCOO${ }^{-*}-\mathrm{Ru}$ during the reaction of ex situ $\mathrm{HCOO}^{-*}$ hydrogenation.

Table 1. Vibrational Modes and Infrared Peak Positions $\left(\mathrm{cm}^{-1}\right)$ of Formate, Bicarbonate, and Carbonate from $\mathrm{CO}_{2}$ Hydrogenation $^{a}$

\begin{tabular}{|c|c|c|c|c|c|c|}
\hline species & $\mathrm{C}-\mathrm{H}$ as. str. & $\mathrm{C}-\mathrm{H}$ b. & $\mathrm{C}=\mathrm{O}$ str. & $\mathrm{O}-\mathrm{C}-\mathrm{O}$ as. str. & $\mathrm{O}-\mathrm{C}-\mathrm{O}$ s. str. & $\mathrm{O}-\mathrm{H} \mathrm{b}$. \\
\hline $\mathrm{HCOOH}$ & $2940(\mathrm{cbn}), 2871,2760(\mathrm{cbn})$ & 1415,1405 & 1748,1670 & 1618,1560 & 1405 ?, 1360 & 1220 \\
\hline $\mathrm{HCOO}^{-*}$-MSI & & 1405 & 1720 & 1618 & $1405 ?$ & 1220 \\
\hline $\mathrm{Br}-\mathrm{HCOO}^{-*}-\mathrm{Ru}$ & 2896 & 1390 & & 1592 & 1375 & 1220 \\
\hline $\mathrm{Bi}-\mathrm{HCOO}^{-*}-\mathrm{Al}_{2} \mathrm{O}_{3}$ & & 1415 & 1710 & 1560 & 1360 & 1230 \\
\hline $\mathrm{HCO}_{3}^{-*}$ & & & 1690 & 1650 & 1440 & 1230 \\
\hline $\mathrm{CO}_{3}{ }^{2-*}$ & & & 1500 & 1450 & & \\
\hline
\end{tabular}

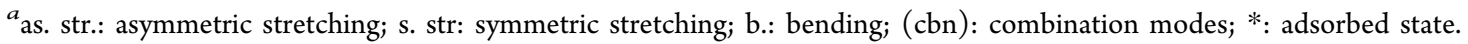

stretching at $2912 \mathrm{~cm}^{-1}$, which gradually red-shifted to 2896 $\mathrm{cm}^{-1}$ during the reaction, also varied similarly as $1592 \mathrm{~cm}^{-1}$ (Figure S3). Thus, the peak at $2896 \mathrm{~cm}^{-1}$ could be classified as $\mathrm{C}-\mathrm{H}$ stretching and a companion of the peak at $1592 \mathrm{~cm}^{-1}$.

The splitting value between the asymmetric and symmetric stretchings $\left(\Delta \nu=\nu_{\text {as }}-\nu_{\mathrm{s}}\right)$ of $\mathrm{O}-\mathrm{C}-\mathrm{O}$ of $\mathrm{HCOO}^{-*}$ also indicates the orientations of the adsorption. For free and bridged formate, $\Delta \nu=220-280 \mathrm{~cm}^{-1}$. When $\Delta \nu$ is smaller than $220 \mathrm{~cm}^{-1}$, formate is a bidentate structure; when $\Delta \nu$ is larger than $280 \mathrm{~cm}^{-1}$, formate is a monodentate structure. ${ }^{15}$ Therefore, formate with the $\mathrm{O}-\mathrm{C}-\mathrm{O}$ asymmetric stretching and symmetric stretching at 1592 and $1375 \mathrm{~cm}^{-1}$, respectively, is in bridged orientation; formate with the $\mathrm{O}-\mathrm{C}-\mathrm{O}$ symmetric stretching at 1560 and $1360 \mathrm{~cm}^{-1}$ is in bidentate orientation. As has been explained above, formates with main peaks at 1592 and $1560 \mathrm{~cm}^{-1}$ are on $\mathrm{Ru}$ and $\mathrm{Al}_{2} \mathrm{O}_{3}$ sites, respectively; these two formates are abbreviated as $\mathrm{Br}_{-} \mathrm{HCOO}^{-} * \mathrm{Ru}$ and $\mathrm{Bi}$ $\mathrm{HCOO}^{-*}-\mathrm{Al}_{2} \mathrm{O}_{3}$, respectively. Formate with the main peak at $1618 \mathrm{~cm}^{-1}$ is located at the metal-support interface (MSI) because of its enhanced intensity on $\mathrm{Ru} / \mathrm{Al}_{2} \mathrm{O}_{3}$ compared to that on $\mathrm{Al}_{2} \mathrm{O}_{3}$ (Section $\mathrm{S} 1.1$ in $\mathrm{SI}$ ) and is thus named $\mathrm{HCOO}^{-*}$-MSI. The related vibrational modes are listed in Table 1.

3.1.3. Reactivity of the Adsorption Species during Ex Situ $\mathrm{HCOO}^{-*}$ Hydrogenation. The reactive trends of each species were exposed at the same time of fitting as shown in Figure $3 \mathrm{~b}-$ d. Ex situ $\mathrm{HCOO}^{-*}$ on $\mathrm{Ru} / \mathrm{Al}_{2} \mathrm{O}_{3}$ was reduced by $\mathrm{H}_{2}$ at $200{ }^{\circ} \mathrm{C}$ until being fully consumed at $250{ }^{\circ} \mathrm{C}$. Along with the decrease of ex situ $\mathrm{HCOO}^{-*}$, three species emerged (Figures S3 and S4). Those were adsorbed carbon monoxide ( $\left.\mathrm{CO}^{*}\right)$ on $\mathrm{Ru}$, gaseous $\mathrm{CO}_{2}$, and $\mathrm{CH}_{4}$ gas with peaks in the ranges of $2100-1900,2450-2250$, and $3100-2900 \mathrm{~cm}^{-1}$, respectively.
Consequently, ex situ $\mathrm{HCOO}^{-*}$ on $\mathrm{Ru} / \mathrm{Al}_{2} \mathrm{O}_{3}$ was reduced by $\mathrm{H}_{2}$ at $200{ }^{\circ} \mathrm{C}$ until being fully consumed at $250{ }^{\circ} \mathrm{C}$. The products were adsorbed $\mathrm{CO}^{*}$, gaseous $\mathrm{CO}_{2}$, and gaseous $\mathrm{CH}_{4}$. $\mathrm{CO}^{*}$ came either from $\mathrm{CO}_{2}$ reduction or from formate decomposition because $\mathrm{CO}^{*}$ increased at the same temperature as $\mathrm{CO}_{2}$ formation and kept increasing until $230{ }^{\circ} \mathrm{C}$, whereas both $\mathrm{CO}_{2}$ and formate were reduced. $\mathrm{CH}_{4}$ also came either from formate or from $\mathrm{CO}_{2}$ hydrogenation because $\mathrm{CH}_{4}$ increased from 220 to $250{ }^{\circ} \mathrm{C}$, whereas both formate and $\mathrm{CO}_{2}$ reduced between 200 and $250{ }^{\circ} \mathrm{C}$. There was no evidence of conversion between $\mathrm{CO}^{*}$ and $\mathrm{CH}_{4}$ because the concentrations of both $\mathrm{CO}^{*}$ and $\mathrm{CH}_{4}$ did not change above $270{ }^{\circ} \mathrm{C}$.

In comparison, ex situ $\mathrm{HCOO}^{-*}$ hydrogenation on $\mathrm{Al}_{2} \mathrm{O}_{3}$ produced noticeable gaseous $\mathrm{CO}$ above $200{ }^{\circ} \mathrm{C}$, which was represented by the occurrence of the rotational-vibrational peaks centered at $2142 \mathrm{~cm}^{-1}$ (Figure S2e), and invariant adsorbed $\mathrm{CO}_{2}{ }^{*}$, which was represented by $\mathrm{O}=\mathrm{C}=\mathrm{O}$ symmetric stretching and resonance at 1387 and $1288 \mathrm{~cm}^{-1}$, respectively (Figure S2f).

3.2. BEGF Analysis of the Spectra of $\mathrm{CO}_{2}$ Hydrogenation. 3.2.1. Convergence of Fitting. The information of the adsorption species during $\mathrm{CO}_{2}$ hydrogenation on $\mathrm{Ru} /$ $\mathrm{Al}_{2} \mathrm{O}_{3}$ was mainly in the overlapped peaks below $2100 \mathrm{~cm}^{-1}$, including $\mathrm{HCO}_{3}{ }^{-*}, \mathrm{CO}_{3}{ }^{2-*}, \mathrm{HCOO}^{-*}$, and $\mathrm{CO}^{*}$, as we presented in our previous work. ${ }^{14}$ The main contribution of this work is the methodology of decoupling the peaks and understanding their meaning via the BEGF program. The initial values of peak positions in BEGF were taken from the IR bands of the samples of carbonates and bicarbonates (Figure S5). Even though the initial values can also be used in regular multipeak Gaussian fitting procedures, the pseudosolutions from the local optima require the heavy manual work of 
repeatedly adjusting the initial values to reach consistent results, including the number of Gaussian peaks, peak positions, and the variations of the integrated intensity for the related experiments. With the BEGF program, the spectral set of $\mathrm{CO}_{2}$ hydrogenation was resolved by global solution within one day (Figure S6), and the fitted results are consistent with the results of our previous publication, obtained by an inefficient Gaussian fitting.

3.2.2. Assignment of Adsorption Species Based on the Kinetic Results. By comparing the trend of the integrated intensity of each peak along with the reaction coordinate (details in the following paragraphs), we found several groups of peaks in the wavenumber range of $1800-1480 \mathrm{~cm}^{-1}$ (Figure 4): group I: 1560 and $1360 \mathrm{~cm}^{-1}$; group II: 1618 and 1405

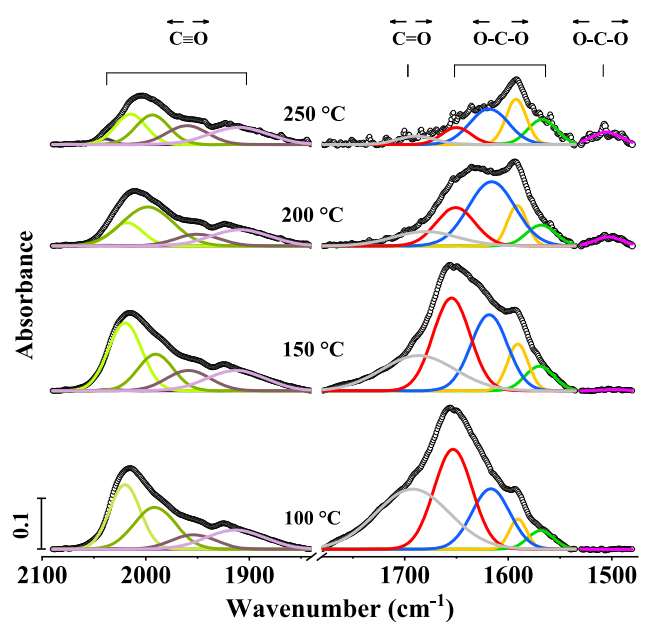

Figure 4. Spectra of $\mathrm{CO}_{2}$ hydrogenation on $\mathrm{Ru} / \mathrm{Al}_{2} \mathrm{O}_{3}$ (black circles) with fitted Gaussian peaks (colored lines) in the ranges of 2100$1840,1780-1535$, and $1530-1480 \mathrm{~cm}^{-1}$. The vibrations in the range of $2100-1840 \mathrm{~cm}^{-1}$ are $\mathrm{C} \equiv \mathrm{O}$ asymmetric stretching and in $1780-$ $1535 \mathrm{~cm}^{-1}$ are the $\mathrm{O}-\mathrm{C}-\mathrm{O}$ asymmetric stretching of $\mathrm{Bi}-\mathrm{HCOO}^{-*}$. $\mathrm{Al}_{2} \mathrm{O}_{3}$ (green peak), $\mathrm{HCOO}^{-*}$-MSI (blue peak), $\mathrm{Br}-\mathrm{HCOO}^{-*}$-Ru (yellow peak), $\mathrm{HCO}_{3}^{-*}$ (red peak), and $\mathrm{CO}_{3}^{2-*}$ (magenta).

$\mathrm{cm}^{-1}$; group III: $2895,1592,1390$, and $1375 \mathrm{~cm}^{-1}$; group IV: 1650, 1440, and $1230 \mathrm{~cm}^{-1}$; and group V: 1500 and 1460 $\mathrm{cm}^{-1}$. Based on the assignment of formate from Section 3.1

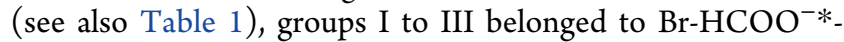
$\mathrm{Ru}, \mathrm{HCOO}^{-*}$-MSI, and $\mathrm{Bi}-\mathrm{HCOO}^{-*}-\mathrm{Al}_{2} \mathrm{O}_{3}$, respectively. Referring to the measured peaks from the reference samples (Figure S5), groups IV and $\mathrm{V}$ belonged to adsorbed bicarbonate $\left(\mathrm{HCO}_{3}{ }^{-*}\right)$ and adsorbed carbonate $\left(\mathrm{CO}_{3}{ }^{2-*}\right)$, respectively. The splitting value of the $\mathrm{O}-\mathrm{C}-\mathrm{O}$ asymmetric $\left(\nu_{\text {as }}\right)$ and symmetric $\left(\nu_{\mathrm{s}}\right)$ stretching bands of $\mathrm{CO}_{3}{ }^{2-*}$ corresponds to different adsorption orientations. A splitting value $\left(\Delta \nu=\nu_{\text {as }}-\nu_{\mathrm{s}}\right)$ less than $100 \mathrm{~cm}^{-1}$ relates to a monodentate structure, $\Delta \nu$ larger than $200 \mathrm{~cm}^{-1}$ relates to a bidentate structure, and $\Delta \nu$ larger than $300 \mathrm{~cm}^{-1}$ relates to a bridged structure. ${ }^{8}$ Since $\Delta \nu$ was far less than $100 \mathrm{~cm}^{-1}$ in our case, $\mathrm{CO}_{3}{ }^{2-*}$ must be adsorbed on the surface with a monodentate structure. Its precursor $\mathrm{HCO}_{3}^{-*}$, which has a similar molecular structure, could also be monodentate.

In the wavenumber range of $2100-1800 \mathrm{~cm}^{-1}$, five adsorption structures of $\mathrm{CO}^{*}$ were deconvoluted with peaks at 2035, 2015, 1990, 1950, and $1905 \mathrm{~cm}^{-1}$. The high frequency at $2035 \mathrm{~cm}^{-1}$ was assigned to linear $\mathrm{CO}^{*}$ on $\mathrm{Ru}^{0}$; the peak at $2015 \mathrm{~cm}^{-1}$ was assigned to linear $\mathrm{CO}^{*}$ on isolated $\mathrm{Ru}^{0}$ surrounded by partially oxidized $\mathrm{Ru}^{\delta+}$; the low frequencies at 1990, 1950, and $1905 \mathrm{~cm}^{-1}$ corresponded to bridged CO*.7,12,17

3.2.2.1. Isotope Spectra. To assist the peak assignment, especially to separate the strongly overlapped frequencies of $\mathrm{O}-\mathrm{C}-\mathrm{O}$ symmetric stretching and $\mathrm{C}-\mathrm{H}$ bending modes, we have done the isotopic experiments with ${ }^{13} \mathrm{CO}_{2}$ at the same conditions as $\mathrm{CO}_{2}$ hydrogenation. As shown in Figure 5a,b, there are certain shifts to the low frequency of the assigned peaks compared to the rich carbon species, including the shift of the $\mathrm{C}-\mathrm{H}$ stretching of $\mathrm{CH}_{4}$ from 3016 to $3007 \mathrm{~cm}^{-1}$, the shift of the $\mathrm{C}-\mathrm{H}$ bending of $\mathrm{CH}_{4}$ from 1306 to $1297 \mathrm{~cm}^{-1}$, and the shift of the center of the $\mathrm{O}=\mathrm{C}=\mathrm{O}$ asymmetric stretching of $\mathrm{CO}_{2}$ from 2350 to $2283 \mathrm{~cm}^{-1}$. The rest of the peak positions of the adsorption species are listed in Table 2. ${ }^{13} \mathrm{C}$ spectra facilitated to confirm the strong peaks of asymmetric stretching modes. However, it did not help the separation of $\mathrm{O}-\mathrm{C}-\mathrm{O}$ symmetric stretching and $\mathrm{C}-\mathrm{H}$ bending modes. This could be understood that ${ }^{13} \mathrm{C}$ shifted the $\mathrm{O}-\mathrm{C}-\mathrm{O}$ symmetric stretching and $\mathrm{C}-\mathrm{H}$ bending modes simultaneously as they both contain carbon bonds. Moreover, the signal/noise ratio did not improve as the intensity of infrared absorbance decreased due to the heavier mass.

Instead of using ${ }^{13} \mathrm{C}$, we considered that $\mathrm{D}_{2}$ could be more helpful to separate $\mathrm{O}-\mathrm{C}-\mathrm{O}$ and $\mathrm{C}-\mathrm{H}$ vibrations. Because $\mathrm{C}-$ $\mathrm{H}$ would be changed to $\mathrm{C}-\mathrm{D}$, the vibrational frequency could be moved away from $\mathrm{O}-\mathrm{C}-\mathrm{O}$ vibrational frequency in the infrared spectra. Therefore, we did $\mathrm{CO}_{2}$ deuteration by mixing 200 mbar $\mathrm{CO}_{2}$ and 800 mbar pure $\mathrm{D}_{2}$ using the same conditions and procedures. Unfortunately, the peak intensities were weakened more significantly in the low-frequency region $\left(<1500 \mathrm{~cm}^{-1}\right)$ (Figure $5 \mathrm{c}, \mathrm{d}$ ). Except for the obvious peaks from $\mathrm{CD}_{x} \mathrm{H}_{4-x}(x=2,3,4),{ }^{16}$ only slight shifts of the strong peaks of the adsorption species were observed (Table 3 ).

Moreover, the reaction kinetics of these two isotopic experiments did not fully match the $\mathrm{CO}_{2}$ hydrogenation results. For instance, the onset and ending temperatures of methane production are higher and lower, respectively, compared to those in the $\mathrm{CO}_{2}$ hydrogenation experiment; the peak intensities were plausibly monotonically increasing/ decreasing, nevertheless in fact occurring complicated shifts at high temperature $\left(>150{ }^{\circ} \mathrm{C}\right)$. The similar phenomena were observed in the spectra of ${ }^{13} \mathrm{CO}_{2}$ hydrogenation in DRIFTS in ref 1 . An investigation of the isotopic effect and comprehensive analysis of the kinetics from these isotopic data await future work to qualify the conclusions.

3.2.3. Reactivities of Adsorption Species during $\mathrm{CO}_{2}$ Hydrogenation. 3.2.3.1. In Situ $\mathrm{HCOO}^{-*}$. To distinguish the formate from the ex situ $\mathrm{HCOO}^{-*}$ in Section 3.1, we named the formate formed from the $\mathrm{CO}_{2}$ hydrogenation process as in situ $\mathrm{HCOO}^{-*}$. $\mathrm{Bi}-\mathrm{HCOO}^{-*}-\mathrm{Al}_{2} \mathrm{O}_{3}$ increased very slightly during the whole reaction (Figure 6a), indicating an inactive property. $\mathrm{HCOO}^{-*}$-MSI was abundant and stable at up to 220 ${ }^{\circ} \mathrm{C}$, after which it was consumed until its disappearance at 300 ${ }^{\circ} \mathrm{C}$ (Figure 6b), consistent with the result of the conversion equilibrium between $\mathrm{HCOO}^{-*}$-MSI and $\mathrm{CO}_{2}^{-*}$ (Section S2.1 in SI). Conversely, $\mathrm{Br}_{-} \mathrm{HCOO}^{-*}-\mathrm{Ru}$ increased from 70 to 150 ${ }^{\circ} \mathrm{C}$, followed by a slow decrease (Figure $6 \mathrm{c}$ ), implying multiple kinetic steps.

These in situ $\mathrm{HCOO}^{-*}$ species exhibited reactivities different from those of ex situ $\mathrm{HCOO}^{-*}$ species in the hydrogenation reaction. For in situ $\mathrm{HCOO}^{-*}, \mathrm{Bi}_{-} \mathrm{HCOO}^{-*}$ $\mathrm{Al}_{2} \mathrm{O}_{3}$ was inert, $\mathrm{HCOO}^{-*}$-MSI was the most reactive species 

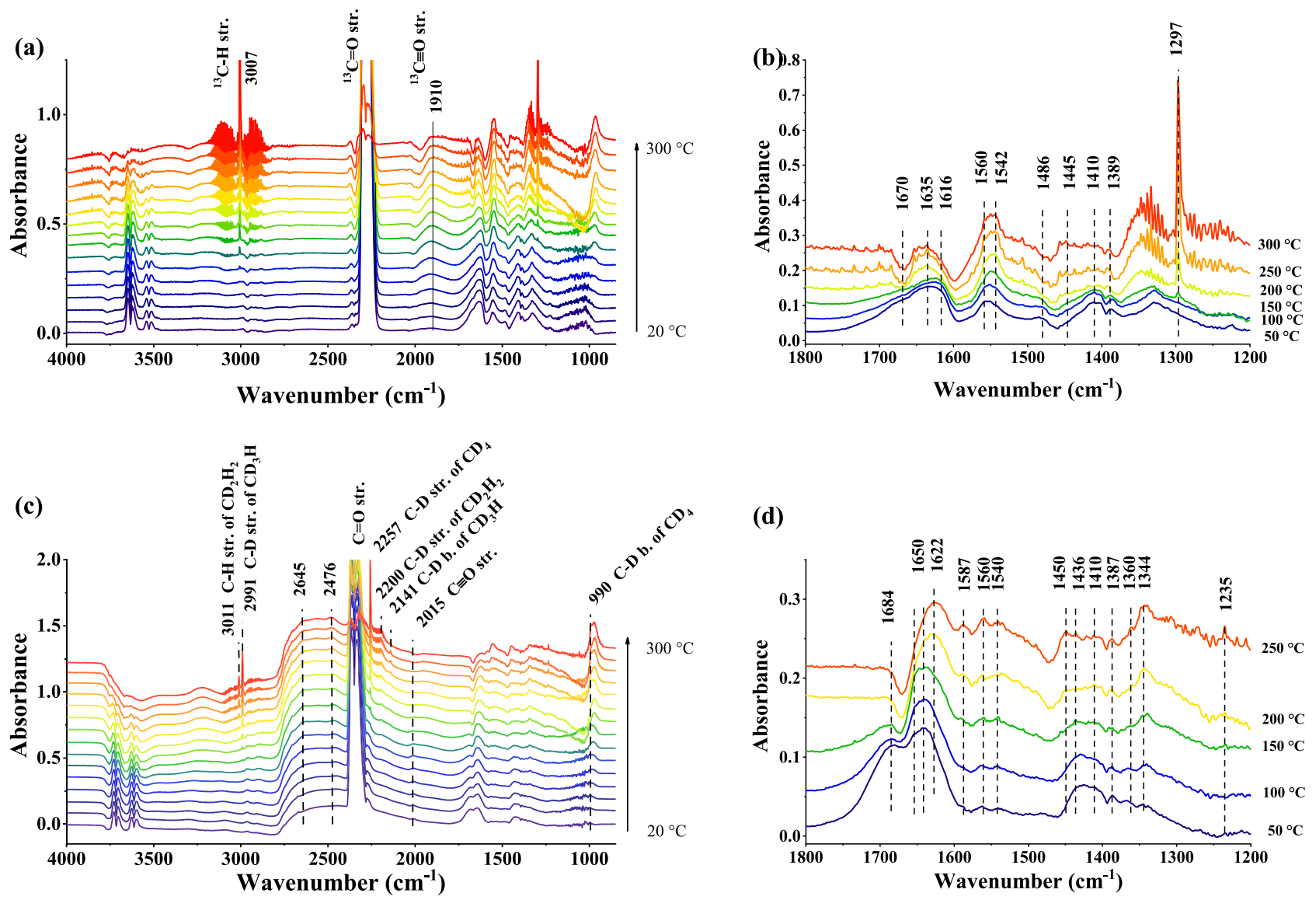

Figure 5. Full infrared spectra of (a) ${ }^{13} \mathrm{CO}_{2}$ hydrogenation by mixing $200 \mathrm{mbar}{ }^{13} \mathrm{CO}_{2}$ and $800 \mathrm{mbar} \mathrm{H}_{2}$, after heating from 20 to $300{ }^{\circ} \mathrm{C}$ at $1{ }^{\circ} \mathrm{C} /$ min, (c) $\mathrm{CO}_{2}$ deuteration in pure $\mathrm{D}_{2}$ by mixing $200 \mathrm{mbar} \mathrm{CO}_{2}$ and $800 \mathrm{mbar} \mathrm{D}_{2}$, after heating from 20 to $300{ }^{\circ} \mathrm{C}$ at $1{ }^{\circ} \mathrm{C} / \mathrm{min}$. The extracted spectra in the wavenumber range between 1800 and $1200 \mathrm{~cm}^{-1}$ from (b) ${ }^{13} \mathrm{CO}_{2}$ hydrogenation and (d) $\mathrm{CO}_{2}$ deuteration.

Table 2. Vibrational Modes and Infrared Peak Positions $\left(\mathrm{cm}^{-1}\right)$ of ${ }^{13} \mathrm{C}$-Formate, -Bicarbonate, and -Carbonate from ${ }^{13} \mathrm{CO}_{2}$ Hydrogenation

\begin{tabular}{|c|c|c|c|c|}
\hline species & $\begin{array}{c}{ }^{13} \mathrm{C}=\mathrm{O} \\
\text { str. }\end{array}$ & $\begin{array}{c}\mathrm{O}-{ }^{13} \mathrm{C}-\mathrm{O} \text { as. } \\
\text { str. }\end{array}$ & $\begin{array}{c}\mathrm{O}-{ }^{13} \mathrm{C}-\mathrm{O} \text { s. } \\
\text { str. }\end{array}$ & $\begin{array}{c}\mathrm{O}-\mathrm{H} \\
\mathrm{b} .\end{array}$ \\
\hline $\mathrm{H}^{13} \mathrm{COO}^{-*}$-MSI & 1700 & 1616 & & 1220 \\
\hline $\mathrm{Br}-\mathrm{H}^{13} \mathrm{COO}^{-*}-\mathrm{Ru}$ & & 1575 & & \\
\hline $\mathrm{Bi}-\mathrm{H}^{13} \mathrm{COO}^{-*}-\mathrm{Al}_{2} \mathrm{O}_{3}$ & & & & \\
\hline $\mathrm{H}^{13} \mathrm{CO}_{3}^{-*}$ & 1670 & 1635 & & 1230 \\
\hline
\end{tabular}

Table 3. Vibrational Modes and Infrared Peak Positions $\left(\mathrm{cm}^{-1}\right)$ of D-Formate, -Bicarbonate, and -Carbonate from $\mathrm{CO}_{2}$ Hydrogenation in Pure $\mathrm{D}_{2}{ }^{a}$

\begin{tabular}{lcccc}
\multicolumn{1}{c}{ species } & $\begin{array}{c}\mathrm{C}=\mathrm{O} \\
\text { str. }\end{array}$ & $\begin{array}{c}\mathrm{O}-\mathrm{C}-\mathrm{O} \text { as. } \\
\text { str. }\end{array}$ & $\begin{array}{c}\mathrm{O}-\mathrm{C}-\mathrm{O} \text { s. } \\
\text { str. }\end{array}$ & $\begin{array}{c}\mathrm{O}-\mathrm{D} \\
\text { b. }\end{array}$ \\
$\mathrm{DCOO}^{-*}-\mathrm{MSI}$ & 1705 & 1622 & 1410 & \\
${\mathrm{Br}-\mathrm{DCOO}^{-*}-\mathrm{Ru}}$ & & 1587 & & \\
${\mathrm{Bi}-\mathrm{DCOO}^{-*}-\mathrm{Al}_{2} \mathrm{O}_{3}}$ & & 1560 & & \\
$\mathrm{DCO}_{3}{ }^{-*}$ & 1684 & 1659 & 1436 & 1230 \\
$\mathrm{CO}_{3}{ }^{2-*}$ & & 1500 & 1450 &
\end{tabular}

${ }^{a}$ Note: carbon not labeled is regular ${ }^{12} \mathrm{C}$.

toward reduction, and $\mathrm{Br}-\mathrm{HCOO}^{-*}$ - $\mathrm{Ru}$ was formed during the reaction until $150{ }^{\circ} \mathrm{C}$ and was then consumed. For ex situ $\mathrm{HCOO}^{-*}, \mathrm{Bi}_{-} \mathrm{HCOO}^{-*}-\mathrm{Al}_{2} \mathrm{O}_{3}$ and $\mathrm{HCOO}^{-*}$-MSI were the most reactive species toward reduction and $\mathrm{Br}-\mathrm{HCOO}^{-*}-\mathrm{Ru}$ increased between 100 and $220^{\circ} \mathrm{C}$, followed by a decrease.

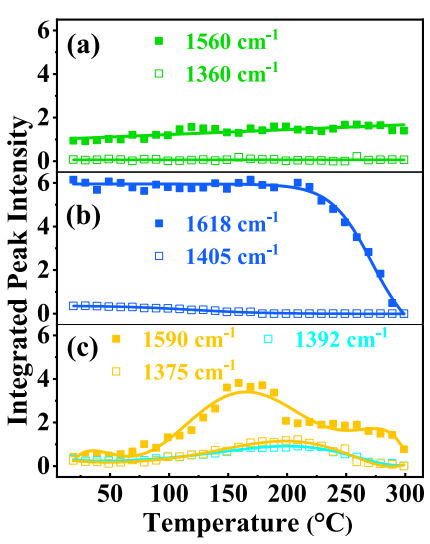

Figure 6. Fitting result of the evolution of (a) $\mathrm{Bi}-\mathrm{HCOO}^{-*}-\mathrm{Al}_{2} \mathrm{O}_{3}$, (b) $\mathrm{HCOO}^{-*}$-MSI, and (c) $\mathrm{Br}-\mathrm{HCOO}^{-*}$-Ru during the $\mathrm{CO}_{2}$ hydrogenation.

Therefore, the ex situ $\mathrm{HCOO}^{-*}$ assists in the peak assignments for in situ $\mathrm{HCOO}^{-*}$ but not in the prediction of the reactivities of the species.

3.2.3.2. $\mathrm{HCO}_{3}{ }^{-*}$ and $\mathrm{CO}_{3}{ }^{2-*} \cdot \mathrm{HCO}_{3}{ }^{-*}$ on $\mathrm{Ru} / \mathrm{Al}_{2} \mathrm{O}_{3}$ decreased slowly below $130{ }^{\circ} \mathrm{C}$ and then accelerated until complete consumption at $300{ }^{\circ} \mathrm{C}$ (Figure 7a). In comparison, $\mathrm{HCO}_{3}{ }^{-*}$ on $\mathrm{Al}_{2} \mathrm{O}_{3}$ was reduced at $100{ }^{\circ} \mathrm{C}$ and fully converted at $160{ }^{\circ} \mathrm{C}$ (Figure S7a,b). This illustrated that $\mathrm{HCO}_{3}{ }^{-*}$ was formed continuously on $\mathrm{Ru} / \mathrm{Al}_{2} \mathrm{O}_{3}$ from $\mathrm{CO}_{2}$ until the $\mathrm{CO}_{2}$ concentration dropped but could not be continuously formed 


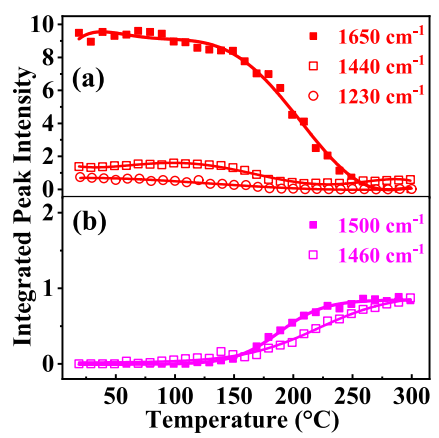

Figure 7. Fitting result of the evolution of (a) $\mathrm{HCO}_{3}^{-*}$ and (b) $\mathrm{CO}_{3}^{2-*}$ during $\mathrm{CO}_{2}$ hydrogenation.

on $\mathrm{Al}_{2} \mathrm{O}_{3}$. In addition, the peak intensity of $\mathrm{HCO}_{3}{ }^{-*}$ was much stronger on $\mathrm{Ru} / \mathrm{Al}_{2} \mathrm{O}_{3}$ than on $\mathrm{Al}_{2} \mathrm{O}_{3}$. These implied that $\mathrm{HCO}_{3}{ }^{-*}$ on $\mathrm{Ru} / \mathrm{Al}_{2} \mathrm{O}_{3}$ was formed at the MSI. $\mathrm{HCO}_{3}{ }^{-*}$ reduction showed a relation with $\mathrm{CO}_{3}{ }^{2-*}$ formation above 200 ${ }^{\circ} \mathrm{C}$ (Figure 7b), indicating a deprotonation process.

3.2.3.3. $\mathrm{CO} *$. Five $\mathrm{CO}^{*}$ on $\mathrm{Ru} / \mathrm{Al}_{2} \mathrm{O}_{3}$ showed distinct reactivities. The linear $\mathrm{CO}^{*}$ on $\mathrm{Ru}^{0}$ was of negligible intensity and invariable, whereas the linear $\mathrm{CO}^{*}$ on isolated $\mathrm{Ru}^{0}$ showed an accumulation till $150{ }^{\circ} \mathrm{C}$ and a consumption afterward (Figure 8a). The bridged $\mathrm{CO}^{*}$ exhibited an increase until 100

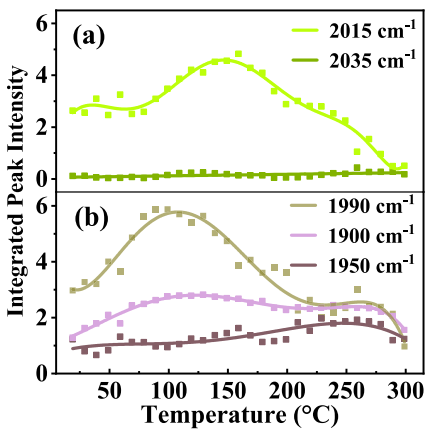

Figure 8. Fitting result of the evolution of (a) linear $\mathrm{CO}^{*}$ and (b) bridged $\mathrm{CO}^{*}$ during the reaction.

${ }^{\circ} \mathrm{C}$, followed by a decrease until reaching an equilibrium level at $200{ }^{\circ} \mathrm{C}$ (Figure $8 \mathrm{~b}$ ). These plots suggested that linear CO* on $\mathrm{Ru}^{0}$ was inactive in $\mathrm{CO}_{2}$ hydrogenation reaction. The other four forms of $\mathrm{CO}^{*}$ participate in the reaction, yet carrying distinct reactivities. It has been reported that the different peak position of $\mathrm{CO}^{*}$ is the result of the changed coverage of CO*., ${ }^{9,17}$ The peak red-shifted when $\mathrm{CO}^{*}$ coverage increased. This happened by supplying low-pressure $\mathrm{CO}$ gas to singlecrystalline metal surfaces at a certain low temperature. ${ }^{18}$ However, in our reaction conditions, the broad $\mathrm{CO}^{*}$ peak showed the evolution of subpeaks related to the kinetics of each adsorption structure of $\mathrm{CO}^{*}$ during the reaction. Among those structures of $\mathrm{CO}^{*}$, linear $\mathrm{CO}^{*}$ on isolated $\mathrm{Ru}^{0}$, surrounded by partially oxidized $\mathrm{Ru}^{\delta+}$, showed a longer accumulation and a faster reduction, indicating a higher reactivity than the other structures of $\mathrm{CO}^{*}$.

On the other hand, $\mathrm{CO}^{*}$ on $\mathrm{Al}_{2} \mathrm{O}_{3}$ generated one broad and weak peak between 2200 and $2100 \mathrm{~cm}^{-1}$. This peak disappeared after pumping to a vacuum (Figure S10), in accordance with results reported for adsorbed $\mathrm{CO}^{*}$ on metal oxides from CO gas. ${ }^{19}$ The weak adsorption and high frequency $\left(>2100 \mathrm{~cm}^{-1}\right)$ of $\mathrm{CO}^{*}$ on $\mathrm{Al}_{2} \mathrm{O}_{3}$ confirmed the strong adsorption and low frequency $\left(<2100 \mathrm{~cm}^{-1}\right)$ of $\mathrm{CO}^{*}$ on $\mathrm{Ru} / \mathrm{Al}_{2} \mathrm{O}_{3}$ adsorbed on $\mathrm{Ru}$ sites.

\section{CONCLUSIONS}

We resolved comprehensively the strongly overlapped and controversial IR peaks of $\mathrm{CO}_{2}$ hydrogenation reaction in DRIFTS by a bi-level evolutionary Gaussian fitting procedure. This procedure allowed the robust and automatic identification of the peaks and their evolution along the reaction coordinate with no need for manual intervention. This method helped to attribute the peaks to the right species and gave the kinetic curves of those species directly. The isotopes ${ }^{13} \mathrm{C}$ and $\mathrm{D}$ were used to assist the assignment of the infrared peaks. From the analysis of ex situ $\mathrm{HCOO}^{-*}$ and $\mathrm{CO}_{2}$ hydrogenation on $\mathrm{Ru}$ / $\mathrm{Al}_{2} \mathrm{O}_{3}$ and on $\mathrm{Al}_{2} \mathrm{O}_{3}$ surfaces, those kinetic curves of the resolved species revealed straightforwardly their reactivities during the reactions. In situ $\mathrm{HCOO}^{-*}$ formed from $\mathrm{CO}_{2}$ hydrogenation was assigned thanks to the peak analysis of ex situ $\mathrm{HCOO}^{-*}$, even though the reactivities of each adsorption structure were distinct from those of ex situ $\mathrm{HCOO}^{-*}$. During $\mathrm{CO}_{2}$ hydrogenation, in situ $\mathrm{HCOO}^{-*}$ adsorbed on the metalsupport interface exhibited a high reactivity, similar to that during $\mathrm{CO}_{2}$ conversion; in situ $\mathrm{HCOO}^{-*}$ adsorbed on $\mathrm{Ru}$ showed less reactivity; and in situ $\mathrm{HCOO}^{-*}$ adsorbed on $\mathrm{Al}_{2} \mathrm{O}_{3}$ was inactive. Bicarbonate also showed high reactivity, similar to that in $\mathrm{CO}_{2}$ conversion. $\mathrm{CO}^{*}$ showed distinctive properties during $\mathrm{CO}_{2}$ hydrogenation, in that it was formed until the middle of the reaction and reduced afterward. These results from BEGF analysis are identical to those of our previous work by manual iteration of Gaussian fitting. This BEGF method is not only suitable for IR spectra but also universal for the deconvolution of overlapping spectra.

\section{ASSOCIATED CONTENT}

\section{Supporting Information}

The Supporting Information is available free of charge on the ACS Publications website at DOI: 10.1021/acs.jpcc.8b11105.

All of the figures mentioned in the main text, including $\mathrm{HCOOH}$ adsorption and hydrogenation on $\mathrm{Al}_{2} \mathrm{O}_{3}$; FTIR transmittance of $\mathrm{Na}_{2} \mathrm{CO}_{3}, \mathrm{CaCO}_{3}, \mathrm{KHCO}_{3}$, and $\mathrm{NaHCO}_{3} ; \mathrm{CO}_{2}$ adsorption and hydrogenation on $\mathrm{Al}_{2} \mathrm{O}_{3}$; the BEGF program (PDF)

\section{AUTHOR INFORMATION}

\section{Corresponding Authors}

*E-mail: kun.zhao@epfl.ch (K.Z.).

*E-mail: marco.calizzi@epfl.ch (M.C.).

ORCID $\odot$

Kun Zhao: 0000-0002-7182-8089

Marco Calizzi: 0000-0001-5319-2657

Author Contributions

${ }^{\perp}$ K.Z. and L.W. contributed equally to this work.

Notes

The authors declare no competing financial interest.

\section{ACKNOWLEDGMENTS}

SCCER HeE, which is financially supported by Innosuisse, the Swiss Innovation Agency, is gratefully acknowledged. K.Z. also gratefully thanks Daniel Auerbach for the full discussions and revisions of this work. 


\section{REFERENCES}

(1) Wang, F.; He, S.; Chen, H.; Wang, B.; Zheng, L.; Wei, M.; Evans, D. G.; Duan, X. Active Site Dependent Reaction Mechanism over $\mathrm{Ru} / \mathrm{CeO}_{2}$ Catalyst toward $\mathrm{CO}_{2}$ Methanation. J. Am. Chem. Soc. 2016, 138, 6298-6305.

(2) Sápi, A.; Halasi, G.; Kiss, J.; Dobó, D. G.; Juhász, K. L.; Kolcsár, V. J.; Ferencz, Z.; Vári, G.; Matolin, V.; Erdőhelyi, A.; et al. In Situ DRIFTS and NAP-XPS Exploration of the Complexity of $\mathrm{CO}_{2}$ Hydrogenation over Size-Controlled Pt Nanoparticles Supported on Mesoporous NiO. J. Phys. Chem. C 2018, 122, 5553-5565.

(3) Martin, N. M.; Hemmingsson, F.; Wang, X.; Merte, L. R.; Hejral, U.; Gustafson, J.; Skoglundh, M.; Meira, D. M.; Dippel, A.-C.; Gutowski, O.; et al. Structure-Function Relationship during $\mathrm{CO}_{2}$ Methanation over $\mathrm{Rh} / \mathrm{Al}_{2} \mathrm{O}_{3}$ and $\mathrm{Rh} / \mathrm{SiO}_{2}$ Catalysts under Atmospheric Pressure Conditions. Catal. Sci. Technol. 2018, 8, 2686-2696.

(4) Xu, M.; Yao, S.; Rao, D.; Niu, Y.; Liu, N.; Peng, M.; Zhai, P.; Man, Y.; Zheng, L.; Wang, B.; et al. Insights into Interfacial Synergistic Catalysis over $\mathrm{Ni} @ \mathrm{TiO}_{2}-\mathrm{x}$ Catalyst toward Water-Gas Shift Reaction. J. Am. Chem. Soc. 2018, 140, 11241-11251.

(5) Zhang, S. R.; Tang, Y.; Nguyen, L.; Zhao, Y. F.; Wu, Z.; Goh, T. W.; Liu, J. J. Y.; Li, Y. Y.; Zhu, T.; Huang, W. Y.; et al. Catalysis on Singly Dispersed Rh Atoms Anchored on An Inert Support. ACS Catal. 2018, 8, 110-121.

(6) Newton, M. A.; Ferri, D.; Smolentsev, G.; Marchionni, V.; Nachtegaal, M. Kinetic Studies of the Pt Carbonate-Mediated, RoomTemperature Oxidation of Carbon Monoxide by Oxygen over Pt/ $\mathrm{Al}_{2} \mathrm{O}_{3}$ Using Combined, Time-Resolved XAFS, DRIFTS, and Mass Spectrometry. J. Am. Chem. Soc. 2016, 138, 13930-13940.

(7) Szanyi, J.; Kwak, J. H. Dissecting the Steps of $\mathrm{CO}_{2}$ Reduction: 2. The Interaction of $\mathrm{CO}$ and $\mathrm{CO}_{2}$ with $\mathrm{Pd} / \gamma-\mathrm{Al}_{2} \mathrm{O}_{3}$ : an In Situ FTIR Study. Phys. Chem. Chem. Phys. 2014, 16, 15126-15138.

(8) Taifan, W.; Boily, J.-F.; Baltrusaitis, J. Surface Chemistry of Carbon Dioxide Revisited. Surf. Sci. Rep. 2016, 71, 595-671.

(9) Marwood, M.; Doepper, R.; Renken, A. In-situ Surface and Gas Phase Analysis for Kinetic Studies under Transient Conditions the Catalytic Hydrogenation of $\mathrm{CO}_{2}$. Appl. Catal., A 1997, 151, 223-246.

(10) Zheng, J.; Wang, C.; Chu, W.; Zhou, Y.; Köhler, K. $\mathrm{CO}_{2}$ Methanation over Supported $\mathrm{Ru} / \mathrm{Al}_{2} \mathrm{O}_{3}$ Catalysts: Mechanistic Studies by In Situ Infrared Spectroscopy. ChemistrySelect 2016, 1, 3197-3203.

(11) Miao, B.; Ma, S. S. K.; Wang, X.; Su, H.; Chan, S. H. Catalysis Mechanisms of $\mathrm{CO}_{2}$ and CO Methanation. Catal. Sci. Technol. 2016, 6, 4048-4058.

(12) Chin, S. Y.; Williams, C. T.; Amiridis, M. D. FTIR Studies of $\mathrm{CO}$ Adsorption on $\mathrm{Al}_{2} \mathrm{O}_{3}$ - and $\mathrm{SiO}_{2}$-Supported Ru Catalysts. J. Phys. Chem. B 2006, 110, 871-882.

(13) Deb, K. An Introduction to Genetic Algorithms. Sadhana 1999, 24, 293-315.

(14) Zhao, K.; Wang, L.; Calizzi, M.; Moioli, E.; Zuttel, A. In Situ Control of the Adsorption Species in $\mathrm{CO}_{2}$ Hydrogenation: Determination of Intermediates and Byproducts. J. Phys. Chem. C 2018, 122, 20888-20893.

(15) Shido, T.; Asakura, K.; Iwasawa, Y. Reactant-Promoted Reaction Mechanism for Catalytic Water-Gas Shift Reaction on MgO. J. Catal. 1990, 122, 55-67.

(16) Wilmshurst, J. K.; Bernstein, H. J. The Infrared Spectra of $\mathrm{CH}_{4}$, $\mathrm{CH}_{3} \mathrm{D}, \mathrm{CH}_{2} \mathrm{D}_{2}, \mathrm{CD}_{3} \mathrm{H}$, and $\mathrm{CD}_{4}$. Can. J. Chem. 1957, 35, 226-235.

(17) Garbarino, G.; Bellotti, D.; Finocchio, E.; Magistri, L.; Busca, G. Methanation of Carbon Dioxide on $\mathrm{Ru} / \mathrm{Al}_{2} \mathrm{O}_{3}$ : Catalytic Activity and Infrared Study. Catal. Today 2016, 277, 21-28.

(18) Hoffmann, F. M. Infrared Reflection-Absorption Spectroscopy of Adsorbed Molecules. Surf. Sci. Rep. 1983, 3, 107-192.

(19) Hadjiivanov, K. I.; Vayssilov, G. N. Characterization of Oxide Surfaces and Zeolites by Carbon Monoxide as an IR Probe Molecule. Adv. Catal. 2002, 47, 307-511. 